\title{
Silver Nanoparticles in Alveolar Bone Surgery Devices
}

\author{
Stefano Sivolella, ${ }^{1,2}$ Edoardo Stellini, ${ }^{3}$ Giulia Brunello, ${ }^{1}$ Chiara Gardin, ${ }^{4}$ Letizia Ferroni, ${ }^{4}$ \\ Eriberto Bressan, ${ }^{2,5}$ and Barbara Zavan ${ }^{4}$ \\ ${ }^{1}$ Department of Oral Surgery, University of Padova Institute of Clinical Dentistry, Via Venezia, 90, 35129 Padova, Italy \\ ${ }^{2}$ Department of Experimental and Diagnostic Medicine, Section of General Pathology, \\ Interdisciplinary Center for the Study of Inflammation (ICSI) and LTTA Center, University of Ferrara, 44121 Ferrara, Italy \\ ${ }^{3}$ Department of Prosthodontics, University of Padova Institute of Clinical Dentistry, Via Venezia, 90, 35129 Padova, Italy \\ ${ }^{4}$ Department of Biomedical Sciences, University of Padova, Via G. Colombo 3, 35100 Padova, Italy \\ ${ }^{5}$ Department of Periodontology, University of Padova Institute of Clinical Dentistry, Via Venezia, 90, 35129 Padova, Italy
}

Correspondence should be addressed to Barbara Zavan, barbara.zavan@unipd.it

Received 15 March 2012; Accepted 11 June 2012

Academic Editor: Sang Cheon Lee

Copyright (c) 2012 Stefano Sivolella et al. This is an open access article distributed under the Creative Commons Attribution License, which permits unrestricted use, distribution, and reproduction in any medium, provided the original work is properly cited.

Silver (Ag) ions have well-known antimicrobial properties and have been applied as nanostrategies in many medical and surgical fields, including dentistry. The use of silver nanoparticles (Ag NPs) may be an option for reducing bacterial adhesion to dental implant surfaces and preventing biofilm formation, containing the risk of peri-implant infections. Modifying the structure or surface of bone grafts and membranes with Ag NPs may also prevent the risk of contamination and infection that are common when alveolar bone augmentation techniques are used. On the other hand, Ag NPs have revealed some toxic effects on cells in vitro and in vivo in animal studies. In this setting, the aim of the present paper is to summarize the principle behind Ag NP-based devices and their clinical applications in alveolar bone and dental implant surgery.

\section{Introduction}

In recent years, silver nanoparticles (Ag NPs) have been studied and suggested for a variety of medical, surgical, and biological applications. Due to their antimicrobial activity, Ag NPs are widely used to reduce burns, chronic ulcers, and wound infections by means of AgNP-impregnated wound dressings [1]. Antimicrobial coatings are especially important in connection with indwelling catheters carrying a high risk of bacterial line infections, such as vascular and urinary catheters $[2,3]$. Ag NPs are also added to surgical instruments, prosthetic devices, and bone replacement materials $[4-6]$.

The oral cavity is populated by a variety of microorganisms. The microbial communities in the oral cavity are polymicrobial and exist primarily as biofilms. These biofilms can be responsible for several local diseases, including periodontal and peri-implant diseases, which can lead to the loss of teeth or implants, respectively, [7]. In fact, "periimplantitis" remains one of the most serious complications after implant placement [8]. The potential of Ag NPs to reduce bacterial adhesion to dental implant surfaces and to prevent biofilm formation has been investigated by many authors $[7,9-12]$ with a view to reducing the risk of periimplant infections.

Another interesting application of Ag NPs in dentistry is for the structural and surface modification of bone grafts and membranes with a view to preventing the risk of contamination and associated infection that are common when bone augmentation techniques such as guided bone regeneration (GBR) and guided tissue regeneration (GTR) are used $[5,13-17]$.

Despite the widespread use of Ag NPs, there is still a shortage of information on their biological effects on human cells and environments. Some authors have investigated the potential toxicity of Ag NPs in different cell 
systems, including bacteria and mammalian cells [18-26]. Such studies have attributed the cytotoxicity of Ag NPs to several possible mechanisms, including the dissolving or release of $\mathrm{Ag}$ ions from the nanoparticles, the disruption of cell membrane integrity, oxidative stress, protein or DNA binding and damage, the generation of reactive oxygen species, and apoptotic cell death [27].

The toxic mechanism seems likely to depend on the nanoparticles' properties too, for example, surface area, size and shape, capping agent, surface charge, particle purity, structural distortion, and the bioavailability of the individual particles [24].

In the light of the above considerations, the aim of the present paper was to describe the antibacterial properties, bone biocompatibility and toxicity of Ag NPs incorporated in devices used for alveolar bone regeneration and in dental implants.

\section{Alveolar Bone Surgery, Controlling Bacterial Infection and Ag NPs}

2.1. Periodontitis and Peri-Implantitis. The most common infectious diseases in alveolar bone are periodontitis and peri-implantitis. Periodontitis is an inflammatory disease caused by infection of the supporting tissue around the teeth. Bacteria are essential to its onset, but not enough to cause the disease, which requires a susceptibility of the host to develop [28].

The prevalence of severe, generalized periodontitis ranges from $5 \%$ to $20 \%$ of any population, while mild-tomoderate periodontitis affects the majority of adults [28].

Peri-implant mucositis is an inflammatory lesion confined to the mucosa, while peri-implantitis also affects the supporting bone [29]. Peri-implantitis is seen in up to $43 \%$ of individuals with implants, and peri-implant mucositis in up to $50 \%$ [30].

Bone loss occurring after initial remodeling is assumed to be due mainly to bacterial infection. The bacterial biofilm forming on implant surfaces is no different from the one that forms on tooth surfaces, but it may be influenced by surface roughness [8]. The initial colonizers that adhere to tooth and implant surfaces include Streptococcus oralis, Streptococcus sanguis, and Streptococcus mitis. There is also a predominant component of Gram-negative species, such as Eikenella corrodens, Veillonella atypica, and Prevotella loeschii. Coaggregation bridges are common between these early colonizers and Fusobacterium nucleatum, which then coaggregates with many late colonizers, which are mostly Gramnegative and anaerobic, and include Aggregatibacter actinomycetemcomitans, Porphyromonas gingivalis, Treponema denticola, Prevotella intermedia, and Tannerella forsythia [3133].

Treatments for periodontal and peri-implant diseases usually include local and systemic measures to combat the infection, and surgical treatment in certain cases to reduce the inflammation and the depth of the periodontal/periimplant pockets, and restore healthy conditions for the soft and hard tissues surrounding the tooth/implant. In some cases, regenerative techniques and materials are used in an effort to regenerate the periodontal or peri-implant soft and hard tissues. The success of such surgical bone regeneration procedures may be negatively affected by infections caused by oral microbia. Chiapasco and Zaniboni [17] conducted a systematic review on the clinical outcome of guided bone regeneration (GBR) procedures for correcting peri-implant dehiscences and fenestrations associated with implant placement. Peri-implant defects were treated with resorbable or nonresorbable membranes, with or without graft materials. In the postoperative period, $20 \%$ of the nonresorbable membranes and $5 \%$ of the resorbable ones became exposed and infected. In the studies considered, the membrane had to be removed in almost all cases of its exposure and infection, lowering the success rate of the GBR procedure.

2.2. Ag NPs Antimicrobial Strategy. Strategies for reducing bacterial adhesion to dental implants seem to be one of the main fields of interest in dental implantology. Ag NPs are among the products of nanotechnology already used in dental practice for their antimicrobial properties and incorporating them in implant coatings may inhibit biofilm formation on the implant surfaces and prevent dental implant failure [7, 9-12]. The use of Ag NPs has also been suggested to reduce the risk of infections after oral regenerative surgery. The presence of silver ions in scaffolds or membranes may prove a desirable measure for minimizing the risk of infections [5, 13-16].

Nanoparticles are routinely defined as particles in sizes ranging between around 1 and $100 \mathrm{~nm}$, and with properties that are not found in bulkier samples of the same material. Nanoparticles have a greater surface-to-volume ratio (per unit of mass) than larger-scale particles of the same material, and are therefore more reactive. Particles smaller than $50 \mathrm{~nm}$ are subject to the laws of quantum physics [34].

Many new methods of synthesis have emerged and are being assessed for the purpose of Ag NP production for medical applications. A number of reports are available in the literature on the synthesis of Ag NPs: from the chemical reduction of silver ions by sodium citrate or sodium borohydride [35]; by reduction into reverse micelles [36]; using biological [37], electrochemical [38], or photochemical methods [39]; radiation [40], laser ablation [41], solvent reduction in the presence of surfactants [42], and sonochemical [43] methods.

There has recently been a renewed interest in the synthesis of organic-inorganic and inorganic-inorganic nanocomposite materials [44].

Nanotechnology is a rapidly-growing field, with nanoparticles being produced and used in a broad range of commercial products all over the world. Several products containing Ag NPs are already on the market. Over the years, the antibacterial activity exhibited by silver compounds and Ag NPs has resulted in their widespread use in bedding, washing machines, water purification, toothpaste, shampoo, nursing bottles, fabrics, deodorants, filters, kitchen utensils, toys, and humidifiers [45].

In particular, Ag NPs have lately emerged in a variety of biomedical applications exploiting their antibacterial 
activity. They have proved to be important in improving wound healing, and, now that several pathogenic bacteria have become resistant to various antibiotics, they could be a safer alternative to conventional antimicrobial agents in topical antimicrobial formulations $[1,46]$.

Due to their antibacterial properties, Ag NPs are also useful for reducing bacterial adhesion and preventing biofilm formation on medical devices, such as catheters or dental implants, where a bacteria-killing activity is highly desirable [47-51].

$\mathrm{Ag}^{+}$ions and $\mathrm{Ag}^{+}$salts have been used for decades as antimicrobial agents in various fields because of their growth-inhibiting effect on microorganisms, but they are of only limited use for a number of reasons-including the interfering effects of salts and the antimicrobial mechanism related to a continuous release of a sufficient concentration of $\mathrm{Ag}^{+}$ion from the metal form-but such drawbacks can be overcome by using Ag NPs. It is essential, however, to be able to prepare the $\mathrm{Ag}^{+}$with cost-effective methods and to understand the mechanism behind their antimicrobial effect [22].

2.3. Ag NPs Mechanism of Action. What gives silver its inhibitory effects on microorganisms is still not entirely clear, and further studies are needed to ascertain all of its properties.

Silver ions inactivate sulfhydryl enzymes when combined with amino, imidazole, carboxyl, and phosphate groups. They also affect DNA replication and stop mitosis in prokaryotes [52].

Some authors believe that silver's antimicrobial activity depends on its ions, which bind strongly to electron donor groups in biological molecules containing sulfur, oxygen, or nitrogen. This may result in defects in the bacterial cell wall, with a consequent loss of the cell's contents. A complex formed by silver ions and proteins may disturb the bacterial cells' metabolism and their power functions (such as permeability and respiration), leading to bacterial cell death. Silver ions can also interact with the DNA of bacteria, preventing cell reproduction $[53,54]$.

Silver interacts with sulfhydryl groups of proteins and DNA, altering hydrogen bonding, respiratory processes, DNA unwinding, cell wall synthesis, and cell division. It also induces denaturation and oxidization of the cell wall, leading to the rupture of the internal cell organelles, and thus resulting in bacterial cell death. Ag NPs also modulate the phosphotyrosine profile of putative bacterial peptides, which could affect bacterial signal transduction and inhibit the organisms' growth [55].

Ag NPs are known to have an antimicrobial activity against Gram-negative bacteria, creating "pits" in the wall of the bacteria. Amro et al. suggested that metal depletion may cause the formation of irregularly shaped pits in the outer membrane and change the membrane's permeability, which is due to the progressive release of lipopolysaccharide molecules and membrane proteins [56].

The specific bactericidal and antiadhesive efficacy of a hydroxyapatite/titania nanocomposite coating on titanium plates on Gram-negative bacteria known to be periodontal and peri-implantitis pathogens, such as Streptococcus mutans, Porphyromonas gingivalis, and Fusohacterium nucleatum was tested by Mo et al. in 2007 [57]; they found that the bactericidal rate on Gram-negative bacteria reached almost $90 \%$ after 3 hours of anaerobic culturing. According to these authors, adding a suitable amount of $\mathrm{Ag}^{+}$ anatase $\mathrm{TiO}_{2}$ prompted a photocatalytic activity without UV light. The existence of $\mathrm{Ag}^{+}$acted beneficially both on the photocatalytic oxidation of $\mathrm{TiO}_{2}$ and as a bactericide. The experimental group also showed am anti-adhesion ability to $S$. mutans and P. gingivalis. After 3 hours of incubation, there were hardly any bacterial cells on the $\mathrm{nAg}-\mathrm{HA} / \mathrm{TiO}_{2}$-coated plates, unlike the situation in the control group.

Liao et al. [58] found that a Ti-AgNP surface had remarkable antibacterial and antiadhesive activities in vitro in relation to Porphyromonas gingivalis and Actinobacillus actinomycetemcomitan, which are two of the main culprits responsible for periodontal and peri-implant diseases. Flores et al. [59] also reported that a modified AgNP-Ti/TiO surface exhibited a good resistance to colonization by Pseudomonas aeruginosa in vitro.

Other studies investigated the effect of Ag NPs, mainly against Escherichia coli and Staphylococcus aureus. The Ag NPs' antimicrobial activity against E. coli was investigated by Sondi and Salopek-Sondi as a model of Gram-negative bacteria [23]. Their study confirmed that the E. coli cells were damaged, showing the formation of "pits" in the cell wall of the bacteria, while the Ag NPs were found to accumulate in the bacterial membrane. A membrane with these morphological features becomes significantly more permeable, resulting in cell death. The antibacterial activity and mechanism of action of Ag NPs on Escherichia coli were also investigated by $\mathrm{Li}$ et al. [60], who analyzed the growth, the permeability, and the morphology of the bacterial cells after treatment with Ag NPs. The experimental results indicated an inhibited growth of $E$. coli cells in vitro. Meanwhile, the Ag NPs prompted reducing sugar and protein leakage, and induced respiratory chain dehydrogenase inactivation, suggesting that they were able to disrupt the bacterial membranes' permeability. These results would indicate that Ag NPs may damage the structure of the bacterial cell membrane and inhibit the activity of some membrane enzymes, eventually causing the death of the $E$. coli bacteria.

Kim et al. [22] tested Ag NPs in three representative microorganisms, that is, yeast, E. coli, and Staphylococcus aureus. They found that yeast and E. coli growth was effectively inhibited. The Ag NPs' antimicrobial activity against yeast and $E$. coli was consistent with the findings reported by Sondi and Salopek-Sondi [23]. The inhibitory effect of Ag NPs was milder on S. aureus than on the other microorganisms, however, giving the impression that the antimicrobial effects of Ag NPs may be associated with the particular characteristics of certain bacterial species. Differences between bacterial species may influence their susceptibility to antibacterial agents.

Gram-positive and Gram-negative bacteria have differences in their membrane structures, the most distinctive 
of which is the thickness of the peptidoglycan layer. The cell walls of Gram-positive species contain 3-20 times more peptidoglycan than those of Gram-negative bacteria. Since peptidoglycans are negatively charged, they probably bind some portion of the silver ions in the broth; this would make Gram-positive bacteria generally less susceptible to antibacterial agents containing silver ions than Gramnegative species [61].

Danilczuk et al. found that $\mathrm{Ag}^{+}$generated free radicals by means of an ESR (electron spin resonance) study on Ag NPs [62]. Kim et al. also observed an $\mathrm{Ag}^{+}$-specific ESR spectrum. The Ag NP peak they obtained in an ESR assay corresponded to the one obtained by Danilczuk et al. To clarify the relationship between free radical and antimicrobial activity, Kim et al. used the antioxidant $\mathrm{N}$ acetylcysteine (NAC) to test whether the antioxidant could influence AgNP-induced antimicrobial activity. The results of ESR tests and antioxidant studies suggest that free radicals may derive from the surface of Ag NPs and be responsible for their antimicrobial activity in the experimental conditions considered [22].

Some researchers have reported that the positive charge on the $\mathrm{Ag}^{+}$ion is crucial for its antimicrobial activity through the electrostatic attraction between the microorganisms' negatively charged cell membrane and the positively charged nanoparticles [6].

The shape of Ag NPs may influence with their antimicrobial effect. Pal et al. [63] found that triangular Ag NPs had a greater biocidal action against E. coli than rod-shaped or spherical nanoparticles. The differences can be explained by the proportion of active facets on the nanoparticles of different shapes. An oriented particulate monolayer X-ray diffraction pattern indicated that triangular nanoparticles have more high-atom-density facets than other shapes, favoring the silver's reactivity. Pal et al. also speculated that the action of Ag NPs is broadly similar to that of silver ions. Sulfur-containing proteins in the membrane or in the cells, as well as phosphorus-containing elements such as DNA, are likely to be the preferential binding sites for Ag NPs.

Another factor that may influence the effectiveness of these particles' antimicrobial activity is their size. In the report from Baker et al. [64], the Ag NPs exhibited antibacterial effects at low concentrations these antibacterial properties correlated with the total surface area of the nanoparticles, that is, smaller particles with a larger surfaceto-volume ratio provided a more efficient medium for antibacterial activity. The nanoparticles were found to be completely cytotoxic for E. coli at surface concentrations as low as 8 microg of $\mathrm{Ag}^{+} / \mathrm{cm}^{2}$.

In agreement with Baker et al., Panáček et al. [53] reported that the antibacterial activity of Ag NPs depended on the size of the silver particles: smaller particles with a larger surface area available for interaction had a greater bactericidal effect than larger particles.

Many studies investigated the antifungal activity of silver nanoparticles against the main fungi frequently found in the oral cavity, but further studies are needed in this area as regards the formulations and means of delivery [65-67].
TABLE 1: Synthesis of the various mechanisms of action of $\mathrm{Ag}^{+}$ions and Ag NPs.

\begin{tabular}{ll}
\hline Author, year & Action \\
\hline Sondi and Salopek-Sondi, 2004 [23]; & \\
Amro et al., 2000 [56]; & Cell wall Pit formation \\
Li et al., 2010 [60]; & \\
Kawahara et al., 2000 [61]. & \\
Li et al., 2010 [60]; & Protein binding \\
Pal et al., 2007 [63]. & \\
Pal et al., 2007 [63]. & DNA binding \\
Danilczuk et al., 2006 [62]. & Free radicals formation \\
\hline
\end{tabular}

Ag NPs have also shown an antiviral potential, proving active against several types of virus, including human immunodeficiency virus, hepatitis $B$ virus, herpes simplex virus, respiratory syncytial virus, and monkeypox virus [68].

A summary of the antimicrobial activities of Ag NPs is given in Table 1.

\section{Ag NPs and Devices}

The capacity of silver nanoparticles to control the formation of biofilms in the oral cavity, as a result of their antibacterial activity, has led to their use in prosthetic device coatings, as topical agents, and in dental materials. Several devices have recently been proposed for use in the fields of dental implantology, periodontology, and alveolar bone regeneration. The prevention of dental implant contamination by bacteria and the need for biocompatible scaffolds or membranes for use in bone grafts with antibacterial properties (achieved by including silver particles in the scaffold, while maintaining its structure and characteristics) seem to be interesting applications of Ag NPs. Below is a review of some of the devices in which Ag NPs have been used, for example, membranes for guided tissue regeneration (GTR) and guided bone regeneration (GBR) applications, scaffolds for bone regeneration, and dental implant coatings.

3.1. Membranes. Barrier membranes are devices used in GTR/GBR procedures to prevent the rapid ingrowth of fibroblasts and/or epithelial cells in a bony defect where slower-growing bone tissue is desired. Barrier membranes thus keep out the unwanted soft tissues and provide a secluded space into which osteogenic cells can migrate and form new bone.

Over the years, numerous resorbable and nonresorbable membranes have been used for GTR and GBR applications $[69,70]$, but they have been unable to reduce the risk of graft infection, especially when the membranes are exposed to the oral cavity. Antimicrobial membranes have been developed to overcome this problem.

Li et al. [14] analyzed a silver ion-substituted nanohydroxyapatite, titania nanoparticles, and polyamide 66 (Ag$\left.\mathrm{nHA} / \mathrm{TiO}_{2} / \mathrm{PA} 66\right)$ membrane, prepared with the intent of producing an antimicrobial membrane with a gradient porous structure for GBR with good mechanical properties, 
biocompatibility, and antimicrobial activity. Cytocompatibility and bone formation were assessed by both in vitro and animal experiments. In vitro assays were carried out with osteoblastlike cells (MG63), and cell viability, alkaline phosphatase activity (ALP), and morphology of cells cultured on the membrane were ascertained, demonstrating good cell affinity and an increased cell attachment, migration, and proliferation. In vivo experiments resulted in the complete closure of 5-mm bone defects created in the skull of SpragueDawley rats 8 weeks after implantation. The same capabilities were seen for the nHA/PA66 membrane, whereas the cranial defects were still not fully covered by newly formed bone 8 weeks after implantation of the PA66 or empty membranes.

Ye et al. [16] studied the effects of the Ag-nHA$\mathrm{nTiO}_{2} / \mathrm{PA} 66$ membrane on MG63 osteoblastlike cells in vitro; nHA/PA66 and expanded polytetrafluroethylene (e-PTFE) membranes were used for control purposes in their assays. The authors found that the Ag-nHA-nTiO $2 / \mathrm{PA} 66$ membrane had no negative effects on the growth of osteoblastlike cells, while it favored cell adhesion, thus indicating an excellent tissue compatibility.

Consistently with the previous article, the same group of researchers found that the osteogenic activity of AgnHA-nTiO ${ }_{2} / \mathrm{PA} 66$ membranes was comparable with that of conventional e-PTFE membranes in a rat model, proving to be a safe strategy for reducing inflammatory response and enhancing bone regeneration, and thus suggesting interesting prospects for further research and the development in antibacterial GBR membranes [71].

The above findings are summarized in Table 2.

3.2. Scaffolds for Bone Regeneration. Bone augmentation procedures have entailed the use of different methods, including GBR and GTR techniques. Especially in nonspace-making defects, the use of grafts (autografts, allografts, xenografts, or alloplasts) prevents membrane collapse, and the graft provides a scaffold on which bone cells can adhere, migrate, grow, and divide, forming new bone. A suitably macroporous structure is important to ensure rapid vascularization, bone ingrowth and-especially in the case of implant placementbone remodeling, with newly formed bone occupying the site previously taken up by the scaffold [73].

To enhance the regeneration of new bone and reduce the healing time, bone tissue engineering relies on 3 -dimensional scaffolds delivering biofactors to assist bone regeneration. In addition to facilitating new bone deposition, some authors are interested in producing osteoconductive scaffolds with bactericidal properties with a view to controlling infection after alveolar bone surgery.

Wu et al. [13] demonstrated that the Ag-nHA/TiO $2 / \mathrm{PA} 66$ antimicrobial scaffold they developed had a highly porous structure that would be effective for the sustained $\mathrm{Ag}^{+}$release at the bone-implant interface. According to the authors, these scaffolds would provide good mechanical support and protection for cell adhesion, migration and proliferation, and hold promise in clinical application in bone augmentation techniques.

Saravanan et al. [5] analyzed the in vitro antimicrobial activity of another biocomposite bone tissue engineering scaffold containing chitosan/nanohydroxyapatite/nanosilver (CS/nHAp/nAg). The results suggested that CS/nHAp/nAg biocomposite scaffolds have the potential for controlling implant-associated bacterial infection during bone reconstruction surgery thanks to the strong antibacterial activity seen on testing the prepared scaffolds with Gram-positive (S. aureus) and Gram-negative (E. coli) bacterial strains. The $\mathrm{CS} / \mathrm{nHAp} / \mathrm{nAg}$ scaffolds were also found non-toxic for rat osteoprogenitor cells and human osteosarcoma cell lines.

Finally, Schneider et al. [15] assessed the in vivo performance in sheep of synthetic, cotton woollike nanocomposites consisting of a biodegradable poly(lactide-co-glycolide) fibrous matrix containing silver-doped calcium phosphate nanoparticles (PLGA/Ag-CaP). The area of new bone formation measured histomorphometrically 8 weeks after implantation was very similar for the PLGA/CaP (control) and the PLGA/Ag-CaP. In fact, the highly porous PLGA/Ag-CaP scaffolds enabled an efficient cell ingrowth, which facilitated new bone formation everywhere inside the former defect, and also led to the resorption of the biodegradable polymer fibers. No signs of any inflammatory reaction were detected.

These data are summarized in Table 3.

3.3. Dental Implant Surfaces. Peri-implantitis remains one of the most serious complications in dental implant surgery and sometimes necessitates implant removal. In fact, the success and long-term survival of dental implants depend not only on bone-implant osteointegration, but also on the prevention of bacterial infection after placement. Incorporating Ag NPs in implant coatings may inhibit biofilm formation on the surfaces and prevent dental implant failure.

Secinti et al. [74] investigated whether Ag NP coatings could inhibit biofilm formation even in slime-forming bacteria; 20 New Zealand rabbits were randomly divided into two equal groups and had bacteria applied to surgical sites on the iliac crests: screws coated with silver using the sol-gel method were inserted in the rabbits in Group I, uncoated Ti screws in the rabbits in Group II. The rabbits were sacrificed after 28 days, and the screws and adjacent bone were examined under transmission (TEM) and scanning electron microscopy (SEM). The antibacterial effect of Ag NPs was also confirmed microbiologically. All silver-coated screws, but only $10 \%$ of the uncoated titanium screws, were sterile. Biofilm formation was inhibited on all the silvercoated screws, whereas all the uncoated screws developed a biofilm on their surfaces. These findings suggest that AgNPcoated screws are as safe as uncoated titanium screws and that the coating helps to prevent both biofilm formation and infection.

A recent report from Flores et al. [59] describes a method for modifying $\mathrm{Ti} / \mathrm{TiO}_{2}$ surfaces with citrate-capped $\mathrm{Ag}$ NPs. The nanoparticles spontaneously adsorb on the $\mathrm{Ti} / \mathrm{TiO}_{2}$, forming nanometer-sized aggregates consisting of individual Ag NPs that evenly cover the surface. The modified AgNP$\mathrm{Ti} / \mathrm{TiO}_{2}$ surface exhibits a good resistance to colonization by Pseudomonas aeruginosa, a model of biofilm formation.

Ionita et al. [11] demonstrated the synergetic antibacterial effect of a HA-silver coating with Ag NPs by comparing the behavior of such a coating with uncoated samples, and 
TABLE 2: Studies about membranes containing Ag NPs proposed in alveolar bone regenerative surgery.

\begin{tabular}{|c|c|c|c|c|}
\hline Author, year & Type of study & Device & $\begin{array}{l}\text { Description of Ag } \\
\text { NPs included }\end{array}$ & Main results \\
\hline \multirow[t]{2}{*}{ Podsiadlo et al., 2005 [72] } & \multirow[t]{2}{*}{ In vitro } & \multirow[t]{2}{*}{$\begin{array}{l}\text { Layer-by-layer } \\
\text { assembly of nacre-like } \\
\text { nanostructured } \\
\text { composites with } \\
\text { antimicrobial } \\
\text { properties. }\end{array}$} & \multirow[t]{2}{*}{ Ag NPs } & $\begin{array}{l}\text { (i) Excellent structural stability } \\
\text { with no detectable levels of silver } \\
\text { lost over a } 1 \text { month period } \\
\text { (ii) Almost complete growth } \\
\text { inhibition of E. coli over an } 18 \mathrm{~h} \\
\text { period. }\end{array}$ \\
\hline & & & & $\begin{array}{l}\text { (iii) Biocompatibility with the } \\
\text { human osteoblast cell line }\end{array}$ \\
\hline \multirow[t]{2}{*}{ Li et al., 2012 [14] } & \multirow{2}{*}{ In vitro. In vivo (animal) } & \multirow{2}{*}{$\begin{array}{l}\text { Antimicrobial } \\
\text { composite membrane } \\
\text { with an asymmetric } \\
\text { porous structure }\end{array}$} & \multirow[t]{2}{*}{$\mathrm{Ag}-\mathrm{nHA} / \mathrm{TiO}_{2} / \mathrm{PA} 66$} & $\begin{array}{l}\text { (i) In vitro: good cell (osteoblast- } \\
\text { like cells) affinity and increase of } \\
\text { cell attachment, migration, and } \\
\text { proliferation. }\end{array}$ \\
\hline & & & & $\begin{array}{l}\text { (ii) In vivo: complete closure of } 5 \text { - } \\
\text { mm bone defects created in the } \\
\text { skull of Sprague-Dawley rats after } \\
8 \text { weeks of implantation. }\end{array}$ \\
\hline \multirow[t]{2}{*}{ Ye et al., 2011 [16] } & \multirow[b]{2}{*}{ In vitro } & \multirow{2}{*}{$\begin{array}{l}\text { Ag-nHA-nTiO } 2 / \text { PA66 } \\
\text { membrane }\end{array}$} & \multirow[b]{2}{*}{ Ag-nHA-nTiO $2 /$ PA66 } & $\begin{array}{l}\text { (i) No negative effects on growth } \\
\text { of osteoblast-like cells. }\end{array}$ \\
\hline & & & & $\begin{array}{l}\text { (ii) Loose porous structure of the } \\
\text { membrane helped the adhesion } \\
\text { and proliferation of osteoblast- } \\
\text { like cells. }\end{array}$ \\
\hline Zhang et al., 2010 [71] & In vivo (animal) & $\begin{array}{c}\text { Ag-nHA-nTiO } \\
\text { membrane }\end{array}$ & Ag-nHA-nTiO $2 /$ PA66 & $\begin{array}{l}\text { (i) Osteogenic activity compara- } \\
\text { ble with e-PTFE. }\end{array}$ \\
\hline
\end{tabular}

TABLE 3: Studies about scaffolds containing Ag NPs proposed in alveolar bone regenerative surgery.

\begin{tabular}{|c|c|c|c|c|}
\hline Author, year & Type of study & Device & $\begin{array}{l}\text { Description of Ag NPs } \\
\text { included }\end{array}$ & Main results \\
\hline \multirow{2}{*}{ Wu et al., 2010 [13] } & \multirow{2}{*}{ In vitro } & \multirow{2}{*}{$\begin{array}{l}\text { Antimicrobial } \\
\text { composite scaffolds }\end{array}$} & \multirow{2}{*}{ Ag-nHA/TiO $2 /$ PA66 } & $\begin{array}{l}\text { (i) } \mathrm{Ag}^{+} \text {release: time and concen- } \\
\text { tration dependent. }\end{array}$ \\
\hline & & & & $\begin{array}{l}\text { (ii) } \mathrm{Ag}^{+} \text {release properties influ- } \\
\text { enced by the immersion medium. }\end{array}$ \\
\hline \multirow{2}{*}{ Saravanan et al., 2011 [5] } & \multirow{2}{*}{ In vitro } & \multirow{2}{*}{$\begin{array}{l}\text { Bio-composite } \\
\text { scaffold for bone } \\
\text { tissue engineering }\end{array}$} & \multirow{2}{*}{$\begin{array}{l}\text { Chitosan/nano- } \\
\text { hydroxyapatite/nano- } \\
\text { silver }\end{array}$} & $\begin{array}{l}\text { (i) Antibacterial activity against } \\
\text { both Gram-positive and Gram- } \\
\text { negative bacteria. }\end{array}$ \\
\hline & & & & $\begin{array}{l}\text { (ii) Non-toxic to rat osteopro- } \\
\text { genitor cells and human osteosar- } \\
\text { coma cell line. }\end{array}$ \\
\hline \multirow[t]{2}{*}{ Schneider et al., 2011 [15] } & \multirow{2}{*}{ In vivo, animal } & \multirow{2}{*}{$\begin{array}{l}\text { Cotton wool-like } \\
\text { flexible artificial } \\
\text { bone substitutes }\end{array}$} & \multirow{2}{*}{ PLGA/Ag-CaP } & $\begin{array}{l}\text { (i) Bone formation was not neg- } \\
\text { atively influenced by the } 0.4 \% \\
\text { silver. }\end{array}$ \\
\hline & & & & $\begin{array}{l}\text { (ii) Area fraction of new bone in } \\
\text { formation after } 8 \text { weeks implan- } \\
\text { tation in hole defects of long } \\
\text { bone in sheep was very similar for } \\
\text { PLGA/CaP and PLGA/Ag-CaP. }\end{array}$ \\
\hline
\end{tabular}

with samples covered with Ag NPs or hydoxyapatite (HA), or incorporating an antibiotic (Tobrex). The bacteriological experiments performed in vitro demonstrated the efficacy of the silver-coated TiAlZr implants against E. coli bacterial growth. The hydrophilic nature of the coatings investigated increased in the same direction percentage inhibition. The antibacterial effect of the biomimetic coating with Ag NPs was high and similar to that of a biomimetic coating with Ag NPs and antibiotic.

Zhao et al. [9] reviewed the current status of antibacterial coatings on titanium implants, acknowledging that in vivo data on these antibacterial coatings were still scarce and that 
surfaces with both an excellent tissue-integrating ability and good antibacterial properties should be explored.

In a recent study by the same authors [10], titania nanotubes $\left(\mathrm{TiO}_{2}\right.$-NTs) incorporated with $\mathrm{Ag} \mathrm{NPs}$ were fabricated on Ti implants for the purpose of preventing implantassociated infections. The amount of $\mathrm{Ag}^{+}$introduced in the NTs was varied by adjusting the processing parameters. The authors noted in vitro that the NT-Ag killed all the planktonic bacteria in the suspension over the first few days, retaining this ability with no obvious decline for 30 days, which would normally be long enough to prevent postoperative infection in the early and intermediate stages and possibly even late infection around the implant. Although the NT-Ag samples showed some cytotoxicity, this could be contained by controlling the $\mathrm{Ag}^{+}$release rate, and the properties could be further tailored to achieve both long-term antibacterial ability and biointegration.

As mentioned earlier, Mo et al. [57] evaluated the bactericidal and antiadhesive efficacy of rough-surfaced titanium plates coated with silver-hydroxyapatite/titania nanocomposites (nAg-HA/ $\mathrm{TiO}_{2}$ ) in combating oral bacteria, and particularly Gram-negative bacteria, which are known periodontal pathogens and involved in the etiology of peri-implantitis (Porphyromonas gingivalis, Fusohacterium nucleatum, and Streptococcus mutans). The viability of each type of bacteria on the antibacterial film was suppressed to about $10 \%$ after anaerobic incubation for 3 hours. Adherence of the bacteria to the $\mathrm{nAg}-\mathrm{HA} / \mathrm{TiO}_{2}$-coated surfaces was considerably lower than for the uncoated surfaces.

Liao et al. [12] investigated AgNP-modified titanium (Ti$\mathrm{AgNP}$ ) surfaces using a silanization method and demonstrated that titanium (Ti) plates with Ag NPs deposited on them acquired an antibacterial activity. After 24 hours of incubation, 94\% of Staphylococcus aureus and more than 95\% of Escherichia coli were killed on the Ti-AgNP surface. SEM examination of the antiadhesive properties also showed that there were fewer bacteria attached to the Ti-AgNP surface than to an untreated Ti control surface.

Since dental implants, being used in the oral cavity, should also have an antibacterial activity in relation to oral bacteria, Liao et al. [58] also tested the antibacterial and antiadhesive action of a silver nanoparticle-modified titanium (Ti-AgNP) surface in relation to two of the most common periodontal pathogens, that is, Porphyromonas gingivalis and Actinobacillus actinomycetemcomitans. Their findings indicate that the Ti-AgNP surface had remarkable anti-bacterial and antiadhesive effects on $P$. gingivalis and A. actinomycetemcomitans, suggesting that Ti-AgNP is a promising implantable biomaterial in terms of its antibacterial properties. The Ti surfaces modified with Ag NPs also showed no signs of cytotoxicity on cultured human gingival fibroblasts (hGFs), suggesting their potential application also in transgingival abutments, which are an important doorway for bacteria.

Implants are in contact not only with bone but also with gingival tissues, and are partially exposed to the oral cavity. With a view to the rapid achievement of a firm soft tissue seal around dental implants that can resist bacterial invasion, Ma et al. [75] created a surface with a lower cytotoxicity while preserving its antibacterial properties by modifying the Ti surface, immobilizing the AgNP/FGF-2 (fibroblast growth factor 2) compound's bioactive factors on a titania nanotube surface. The immobilized AgNP/FGF-2 samples displayed an excellent cytocompatibility, negligible cytotoxicity, and enhanced hFGF functions such as cell attachment, proliferation, and ECM-related gene expression. The absence of any significant cytotoxicity may be due to the negligible amounts of $\mathrm{Ag}^{+}$ions released by the Ag NP solution, and, as Williams et al. demonstrated [76], small concentrations of $\mathrm{Ag}^{+}$released into the extracts are not cytotoxic. The Ag NPs also exhibited some bioactivity. These results lead to the same conclusions as the previous paper and encourage the use of this material in dental implant abutments.

The data presented above are summarized in Table 4.

\section{Ag NP Toxicity}

The impact of Ag NPs on cell viability has been investigated to establish the feasibility of their use in clinical applications. Several studies have been performed in vitro (on osteoblasts and other cell lines), and in vivo (in animal models) for this purpose.

4.1. In Vitro Studies. Mahmood et al. [77] reported on the in vitro effects of different types of nanomaterial (single-walled carbon nanotubes-SWCNTs, hydroxyapatite nanoparticles-HAP, titanium dioxide nanoparticles- $\mathrm{TiO}_{2}$, and silver nanoparticles-Ag NPs) on cell calcification and mineralization by bone cells. The greatest of cell mineralization enhancement coincided with the use of Ag NPs, followed by HAP, $\mathrm{TiO}_{2}$ and SWCNTs. Ag NPs were found to alter microRNA expression; the numerous transcriptional factors associated with bone formation (Runx2, Dlx3, and Msx2) were affected by correspondent miRNAs only in the bone cells exposed to Ag NPs. Exposure to Ag NPs also resulted in the miRNA regulation of several gene-target BMPs not found in the controls. The authors also said that preliminary cytotoxicity studies performed with the nanoparticle concentrations used in the experiments gave no indication of any onset of cytotoxic effects.

Studying layer-by-layer (LBL) assemblies of nacrelike nanostructured composites containing Ag NPs, Podsiadlo et al. [72] also reported finding no detectable levels in vitro of silver being lost over a 1-month period, associated with a bactericidal effect (E. coli growth was almost completely inhibited over an $18 \mathrm{~h}$ period), and the concentration of silver did not prevent the growth of mammalian tissue cultures. The LBL composite showed biocompatibility with human osteoblast cell lines.

On the other hand, Zhao et al. [10] found in vitro that titania nanotubes $\left(\mathrm{TiO}_{2}\right.$-NTs) incorporating Ag NPs showed some cytotoxicity in primary rat osteoblasts, which could be reduced by controlling the rate of $\mathrm{Ag}^{+}$release.

Albers et al. [78] investigated the cytotoxicity of Ag NPs $(50 \mathrm{~nm})$ in vitro on osteoblasts (OBs) and osteoclasts (OCs) at antibacterial concentrations: they demonstrated that $\mathrm{Ag}$ 
Table 4: Studies about dental implants surfaces containing Ag NPs.

\begin{tabular}{|c|c|c|c|c|}
\hline Author, year & $\begin{array}{l}\text { Type of } \\
\text { study }\end{array}$ & Device & $\begin{array}{l}\text { Description of Ag } \\
\text { NPs included }\end{array}$ & Main results \\
\hline \multirow[t]{2}{*}{ Zhao et al., 2011 [10] } & \multirow[t]{2}{*}{ In vitro } & \multirow[t]{2}{*}{$\begin{array}{l}\text { Coatings for } \\
\text { titanium } \\
\text { implants }\end{array}$} & \multirow{2}{*}{$\begin{array}{l}\text { Titania nanotubes } \\
\left(\mathrm{TiO}_{2}-\mathrm{NTs}\right) \\
\text { incorporated with } \\
\mathrm{Ag} \text { NPs. }\end{array}$} & $\begin{array}{l}\text { (i) The NT-Ag structure } \\
\text { shows some cytotoxicity, that } \\
\text { can be reduced by controlling } \\
\text { the } \mathrm{Ag}^{+} \text {release rate. }\end{array}$ \\
\hline & & & & $\begin{array}{l}\text { (ii) Long-term antibacterial } \\
\text { ability. Satisfactory } \\
\text { osteoconductivity (osteoblast } \\
\text { from rat calvarial bone). }\end{array}$ \\
\hline \multirow{2}{*}{ Secinti et al., 2011 [74] } & \multirow{2}{*}{$\begin{array}{l}\text { In vivo, } \\
\text { animal }\end{array}$} & \multirow{2}{*}{$\begin{array}{l}\text { Coatings on } \\
\text { titanium } \\
\text { implants }\end{array}$} & \multirow[t]{2}{*}{ Ag NPs } & $\begin{array}{l}\text { (i) Biofilm formation } \\
\text { inhibition. }\end{array}$ \\
\hline & & & & $\begin{array}{l}\text { (ii) Nontoxic, and no harmful } \\
\text { side effects detected on the } \\
\text { kidney, liver, brain, or cornea. }\end{array}$ \\
\hline \multirow[b]{2}{*}{ Ionita et al., 2011 [11] } & \multirow[b]{2}{*}{ In vitro } & \multirow{2}{*}{$\begin{array}{l}\text { Coatings on } \\
\text { titanium } \\
\text { implants }\end{array}$} & \multirow[t]{2}{*}{ Ag NPs-HA/TiAlZr } & $\begin{array}{l}\text { (i) Inhibition of growth of } E \text {. } \\
\text { coli bacteria. }\end{array}$ \\
\hline & & & & $\begin{array}{l}\text { (ii) Antibacterial effect of } \\
\text { biomimetic coating with Ag } \\
\text { NPs is high and close to value } \\
\text { of biomimetic coating with } \\
\text { silver and antibiotic (Tobrex). }\end{array}$ \\
\hline Liao et al., 2010 [12] & In vitro & $\begin{array}{l}\text { Coatings on } \\
\text { titanium } \\
\text { implants }\end{array}$ & Ag NPs & $\begin{array}{l}\text { (i) Ti-Ag NPs specimens } \\
\text { significantly inhibited the } \\
\text { growth of both Staphylococcus } \\
\text { aureus and Escherichia coli } \\
\text { than Ti-polished specimen. }\end{array}$ \\
\hline \multirow[t]{2}{*}{ Liao et al., 2010 [58] } & \multirow[t]{2}{*}{ In vitro } & \multirow[t]{2}{*}{$\begin{array}{l}\text { Antibacterial } \\
\text { titanium } \\
\text { plate }\end{array}$} & \multirow[t]{2}{*}{ Ag NPs } & $\begin{array}{l}\text { (i) Ti-Ag NPs surface: } \\
\text { remarkable antibacterial and } \\
\text { antiadhesive activities to } \\
\text { Porphyromonas gingivalis and } \\
\text { Actinobacillus } \\
\text { actinomycetemcomitans. }\end{array}$ \\
\hline & & & & $\begin{array}{l}\text { (ii) No detectable cytotoxicity } \\
\text { on cultured human gingival } \\
\text { fibroblasts (hFGFs). }\end{array}$ \\
\hline Ma et al., 2011 [75] & In vitro & $\begin{array}{l}\text { Modified } \\
\text { titanium } \\
\text { implant } \\
\text { surface }\end{array}$ & $\begin{array}{l}\mathrm{TiO}_{2} \text { nanotubular } \\
\text { surface with } \\
\text { immobilized } \\
\text { compound } \\
\mathrm{Ag} / \mathrm{FGF}-2 \\
\text { (fibroblast growth } \\
\text { factor-2) }\end{array}$ & $\begin{array}{l}\text { (i) } \mathrm{The}_{\mathrm{TiO}} \text { nanotubular } \\
\text { surface with immobilized } \\
\text { compound Ag/FGF-2 has } \\
\text { excellent cytocompatibility } \\
\text { compared to pure Ti. }\end{array}$ \\
\hline Flores et al., 2010 [59] & In vitro & $\begin{array}{l}\text { Coatings on } \\
\text { titanium } \\
\text { implants }\end{array}$ & $\begin{array}{l}\text { Ag NPs } \\
\text { spontaneously } \\
\text { adsorb on } \mathrm{Ti} / \mathrm{TiO}_{2}\end{array}$ & $\begin{array}{l}\text { (i) Good resistance to } \\
\text { colonization by Pseudomonas } \\
\text { aeruginosa. }\end{array}$ \\
\hline Mo et al., 2007 [57] & In vitro & $\begin{array}{l}\text { Coatings on } \\
\text { titanium } \\
\text { plates }\end{array}$ & Ag-HA/TiO 2 & $\begin{array}{l}\text { (i) Antibacterial activity } \\
\text { against: Porphyromonas } \\
\text { gingivalis, Prevotella } \\
\text { intermedia, Fusohacterium } \\
\text { nucleatum, and Streptococcus } \\
\text { mutans. }\end{array}$ \\
\hline
\end{tabular}


NPs had cytotoxic effects on both cell lines, as indicated by dose-dependent decreases in the number of viable cells and differentiations. The inhibitory activity of microparticles of silver $(3 \mu \mathrm{m})$ was significantly weaker, a finding consistent with the results of previous studies [79-81]. According to these authors, the size-dependent cytotoxicity is due to the size- and surface-area-dependent release of silver ions from the particles. OBs were found more susceptible to the AgNPmediated inhibition of cell viability and differentiation than OCs; both OBs and OCs were more susceptible to silver treatment than S. epidermidis. The MICs of $\mathrm{Ag}^{+}$deriving from $\mathrm{AgNO}_{3}$ or Ag NPs used to inhibit bacterial growth were 24 times higher than the minimal $\mathrm{Ag}^{+}$concentration needed to reduce the viability and proliferation of OBs and OCs. Finally, Albers et al. confirmed the antimicrobial properties of Ag NPs on S. epidermidis, but they were critical regarding the biological safety of silver-releasing implantable materials.

Suresh et al. [27] also found that Ag NPs caused celldependent cytotoxicity: their data emphasized the role of surface coatings or surface charges and particle aggregation in dictating the cytotoxicity of Ag NPs, but also showed that the cell type influenced their cytotoxic effect. Lung epithelial cells were more resistant than macrophages to the differently surface-coated Ag NPs being tested.

The results obtained by Greulich et al. [82] confirmed a cell-specific uptake of Ag NPs by peripheral blood mononuclear cells (PBMC) and accordingly different cellular responses after the exposure of monocytes and lymphocytes (T cells).

Ag NPs revealed no detectable cytotoxicity on cultured human gingival fibroblasts (hFGFs) in vitro $[58,75]$.

4.2. In Vivo Studies. Other studies have raised concerns regarding the safety of silver applications in animal models.

Hyun et al. [83] investigated the effects of repeated exposure to Ag NPs on the histological structure and mucins of the nasal respiratory mucosa: rats were exposed to different concentrations of silver nanoparticles in an inhalation chamber for 6 hours a day, 5 times a week for 28 days, after which the animals were sacrificed. The study indicated that the silver nanoparticles influenced the neutral mucins in the respiratory mucosa, but not to a toxicologically significant degree.

Kim et al. [84] found some significant dose-dependent changes in the alkaline phosphatase and cholesterol levels in male and female rats, which seemed to indicate that exposure to more than $300 \mathrm{mg}$ of Ag NPs might result in mild liver damage. Ag NPs were found to induce no genetic toxicity in male or female rat bone marrow in vivo.

In their in vivo study, Secinti et al. [74] investigated the antibacterial effect of silver-coated titanium implants in rabbits, examining their liver, kidney, brain and cornea under transmission (TEM), and scanning electron microscopy (SEM). They detected no harmful side effects in these rabbit organs after the placement of Ag NPs coated screws.

\section{Conclusions}

Ag NPs have been studied as an alternative strategy for reducing bacterial adhesion and preventing biofilm formation thanks to their antimicrobial properties. Ag NPs have been included in devices used in alveolar bone surgery with promising results.

Membranes and scaffolds for bone regeneration containing Ag NPs have the potential to reduce the incidence of postoperative bacterial contamination. One of the most interesting applications of Ag NPs in dentistry is for preventing or delaying peri-implantitis. Ag NP coatings could be applied to the whole dental implant surface or to selected areas, such as the most coronal area of the implant or the inner threaded surface. Another strategy to reduce biofilm formation on dental implants and the related prosthetic components in the oral cavity might be to apply Ag NPs to prosthetic devices such as the healing screws, abutments, and fixing screws.

Published data highlight the importance of surface coatings, surface charge, speed of release, concentration of $\mathrm{Ag}^{+}$, and particle aggregation in dictating the cytotoxicity of Ag NPs, which also seems to depend on the type of cell affected.

Reproducibility issues arising from the type of Ag NP application, the tests conducted and the subjects involved (cell lines or animals) have made any comparison of the results reported in different studies arduous or controversial. For the time being, most of the studies analyzed here were conducted in vitro, and there is a clear need for further clinical trials. In vitro, and animal studies are needed on the devices described, focusing particularly on the oral microbiota responsible for periodontal and peri-implant diseases.

\section{Conflict of Interests}

The authors confirm that there is no conflicts of interests.

\section{References}

[1] K. Madhumathi, P. T. Sudheesh Kumar, S. Abhilash et al., "Development of novel chitin/nanosilver composite scaffolds for wound dressing applications," Journal of Materials Science, vol. 21, no. 2, pp. 807-813, 2010.

[2] K. N. J. Stevens, O. Crespo-Biel, E. E. M. van den Bosch et al., "The relationship between the antimicrobial effect of catheter coatings containing silver nanoparticles and the coagulation of contacting blood," Biomaterials, vol. 30 , no. 22 , pp. $3682-$ 3690, 2009.

[3] M. A. Syed, S. Babar, A. S. Bhatti, and H. Bokhari, "Antibacterial effects of silver nanoparticles on the bacterial strains isolated from catheterized urinary tract infection cases," Journal of Biomedical Nanotechnology, vol. 5, no. 2, pp. 209214, 2009.

[4] M. S. Cohen, J. M. Stern, A. J. Vanni et al., "In vitro analysis of a nanocrystalline silver-coated surgical mesh," Surgical Infections, vol. 8, no. 3, pp. 397-404, 2007.

[5] S. Saravanan, S. Nethala, S. Pattnaik, A. Tripathi, A. Moorthi, and N. Selvamurugan, "Preparation, characterization and 
antimicrobial activity of a bio-composite scaffold containing chitosan/nano-hydroxyapatite/nano-silver for bone tissue engineering," International Journal of Biological Macromolecules, vol. 49, no. 2, pp. 188-193, 2011.

[6] D. R. Monteiro, L. F. Gorup, A. S. Takamiya, A. C. RuvolloFilho, E. R. de Camargo, and D. B. Barbosa, "The growing importance of materials that prevent microbial adhesion: antimicrobial effect of medical devices containing silver," International Journal of Antimicrobial Agents, vol. 34, no. 2, pp. 103-110, 2009.

[7] R. P. Allaker, "The use of nanoparticles to control oral biofilm formation," Journal of Dental Research, vol. 89, no. 11, pp. 1175-1186, 2010.

[8] N. P. Lang and T. Berglundh, "Periimplant diseases: where are we now? - consensus of the Seventh European Workshop on Periodontology," Journal of Clinical Periodontology, vol. 38, no. 11, pp. 178-181, 2011.

[9] L. Zhao, P. K. Chu, Y. Zhang, and Z. Wu, "Antibacterial coatings on titanium implants," Journal of Biomedical Materials Research, vol. 91, no. 1, pp. 470-480, 2009.

[10] L. Zhao, H. Wang, K. Huo et al., "Antibacterial nanostructured titania coating incorporated with silver nanoparticles," Biomaterials, vol. 32, no. 24, pp. 5706-5716, 2011.

[11] D. Ionita, M. Grecu, C. Ungureanu, and I. Demetrescu, "Antimicrobial activity of the surface coatings on TiAlZr implant biomaterial," Journal of Bioscience and Bioengineering, vol. 112, no. 6, pp. 630-634, 2011.

[12] J. Liao, Z. Zhu, A. Mo, L. Li, and J. Zhang, "Deposition of silver nanoparticles on titanium surface for antibacterial effect," International Journal of Nanomedicine, vol. 5, no. 1, pp. 261-267, 2010.

[13] X. Wu, J. Li, L. Wang, D. Huang, Y. Zuo, and Y. Li, "The release properties of silver ions from $\mathrm{Ag}-\mathrm{nHA} / \mathrm{TiO}_{2} / \mathrm{PA} 66$ antimicrobial composite scaffolds," Biomedical Materials, vol. 5, no. 4, Article ID 044105, 2010.

[14] J. Li, Y. Zuo, Y. Man et al., "Fabrication and biocompatibility of an antimicrobial composite membrane with an asymmetric porous structure," Journal of Biomaterials Science, vol. 23, no. 1-4, pp. 81-96, 2012.

[15] O. D. Schneider, D. Mohn, R. Fuhrer et al., "Biocompatibility and bone formation of flexible, cotton wool-like PLGA/calcium phosphate nanocomposites in sheep," The Open Orthopaedics Journal, vol. 5, pp. 63-71, 2011.

[16] J. Ye, Q. Yao, A. Mo et al., "Effects of an antibacterial membrane on osteoblast-like cells in vitro," International journal of nanomedicine, vol. 6, pp. 1853-1861, 2011.

[17] M. Chiapasco and M. Zaniboni, "Clinical outcomes of GBR procedures to correct peri-implant dehiscences and fenestrations: a systematic review," Clinical Oral Implants Research, vol. 20, pp. 113-123, 2009.

[18] P. V. AshaRani, G. L. K. Mun, M. P. Hande, and S. Valiyaveettil, "Cytotoxicity and genotoxicity of silver nanoparticles in human cells," ACS Nano, vol. 3, no. 2, pp. 279-290, 2009.

[19] H. J. Johnston, G. Hutchison, F. M. Christensen, S. Peters, S. Hankin, and V. Stone, "A review of the in vivo and in vitro toxicity of silver and gold particulates: particle attributes and biological mechanisms responsible for the observed toxicity," Critical Reviews in Toxicology, vol. 40, no. 4, pp. 328-346, 2010.

[20] Y. Li, D. H. Chen, J. Yan et al., "Genotoxicity of silver nanoparticles evaluated using the Ames test and in vitro micronucleus assay," Mutation Research/Genetic Toxicology and Environmental Mutagenesis, vol. 745, no. 1-2, pp. 4-10, 2012.
[21] C. Greulich, J. Diendorf, T. Simon, G. Eggeler, M. Epple, and M. Köller, "Uptake and intracellular distribution of silver nanoparticles in human mesenchymal stem cells," Acta Biomaterialia, vol. 7, no. 1, pp. 347-354, 2011.

[22] J. S. Kim, E. Kuk, K. N. Yu et al., "Antimicrobial effects of silver nanoparticles," Nanomedicine, vol. 3, no. 1, pp. 95-101, 2007.

[23] I. Sondi and B. Salopek-Sondi, "Silver nanoparticles as antimicrobial agent: a case study on E. coli as a model for Gramnegative bacteria," Journal of Colloid and Interface Science, vol. 275, no. 1, pp. 177-182, 2004.

[24] A. K. Suresh, D. A. Pelletier, W. Wang et al., "Silver nanocrystallites: biofabrication using shewanella oneidensis, and an evaluation of their comparative toxicity on gram-negative and gram-positive bacteria," Environmental Science \& Technology, vol. 44, no. 13, pp. 5210-5215, 2010.

[25] M. Ahamed, M. Karns, M. Goodson et al., "DNA damage response to different surface chemistry of silver nanoparticles in mammalian cells," Toxicology and Applied Pharmacology, vol. 233, no. 3, pp. 404-410, 2008.

[26] M. Ahamed, M. S. AlSalhi, and M. K. J. Siddiqui, "Silver nanoparticle applications and human health," Clinica Chimica Acta, vol. 411, no. 23-24, pp. 1841-1848, 2010.

[27] A. K. Suresh, D. A. Pelletier, W. Wang, J. L. Morrell-Falvey, B. $\mathrm{Gu}$, and M. J. Doktycz, "Cytotoxicity induced by engineered silver nanocrystallites is dependent on surface coatings and cell types," Langmuir, vol. 28, no. 5, pp. 2727-2735, 2012.

[28] B. Burt, "Position paper: epidemiology of periodontal diseases," Journal of Periodontology, vol. 76, no. 8, pp. 1406-1419, 2005.

[29] J. Lindhe and J. Meyle, "Peri-implant diseases: consensus Report of the Sixth European Workshop on Periodontology," Journal of Clinical Periodontology, vol. 35, supplement 8, pp. 282-285, 2008.

[30] N. U. Zitzmann and T. Berglundh, "Definition and prevalence of peri-implant diseases," Journal of Clinical Periodontology, vol. 35, no. 8, pp. 286-291, 2008.

[31] S. S. Socransky and A. D. Haffajee, "Periodontal microbial ecology," Periodontology 2000, vol. 38, pp. 135-187, 2005.

[32] S. S. Socransky, C. Smith, and A. D. Haffajee, "Subgingival microbial profiles in refractory periodontal disease," Journal of Clinical Periodontology, vol. 29, no. 3, pp. 260-268, 2002.

[33] P. E. Kolenbrander, R. J. Palmer, A. H. Rickard, N. S. Jakubovics, N. I. Chalmers, and P. I. Diaz, "Bacterial interactions and successions during plaque development," Periodontology 2000, vol. 42, no. 1, pp. 47-79, 2006.

[34] M. Auffan, J. Rose, J. Y. Bottero, G. V. Lowry, J. P. Jolivet, and M. R. Wiesner, "Towards a definition of inorganic nanoparticles from an environmental, health and safety perspective," Nature Nanotechnology, vol. 4, no. 10, pp. 634-641, 2009.

[35] P. V. Kamat, M. Flumiani, and G. V. Hartland, "Picosecond dynamics of silver nanoclusters. Photoejection of electrons and fragmentation," The Journal of Physical Chemistry B, vol. 102, no. 17, pp. 3123-3128, 1998.

[36] A. Taleb, C. Petit, and M. P. Pileni, "Synthesis of highly monodisperse silver nanoparticles from AOT reverse micelles: a way to 2D and 3D self-organization," Chemistry of Materials, vol. 9, no. 4, pp. 950-959, 1997.

[37] R. R. Naik, S. J. Stringer, G. Agarwal, S. E. Jones, and M. O. Stone, "Biomimetic synthesis and patterning of silver nanoparticles," Nature Materials, vol. 1, no. 3, pp. 169-172, 2002.

[38] L. Rodríguez-Sánchez, M. C. Blanco, and M. A. LópezQuintela, "Electrochemical synthesis of silver nanoparticles," 
The Journal of Physical Chemistry B, vol. 104, no. 41, pp. $9683-$ $9688,2000$.

[39] H. H. Huang, X. P. Ni, G. L. Loy et al., "Photochemical formation of silver nanoparticles in poly(N-vinylpyrrolidone)," Langmuir, vol. 12, no. 4, pp. 909-912, 1996.

[40] N. M. Dimitrijevic, D. M. Bartels, C. D. Jonah, K. Takahashi, and T. Rajh, "Radiolytically induced formation and optical absorption spectra of colloidal silver nanoparticles in supercritical ethane," Journal of Physical Chemistry B, vol. 105, no. 5, pp. 954-959, 2001.

[41] F. Mafuné, J. Y. Kohno, Y. Takeda, and T. Kondow, "Structure and stability of silver nanoparticles in aqueous solution produced by laser ablation," Journal of Physical Chemistry B, vol. 104, no. 35, pp. 8336-8337, 2000.

[42] G. Rodríguez-Gattorno, D. Díaz, L. Rendón, and G. O. Hernández-Segura, "Metallic nanoparticles from spontaneous reduction of silver(I) in DMSO. Interaction between nitric oxide and silver nanoparticles," Journal of Physical Chemistry B, vol. 106, no. 10, pp. 2482-2487, 2002.

[43] V. G. Pol, D. N. Srivastava, O. Palchik et al., "Sonochemical deposition of silver nanoparticles on silica spheres," Langmuir, vol. 18, no. 8, pp. 3352-3357, 2002.

[44] S. K. Arumugam, T. P. Sastry, B. Sreedhar, and A. B. Mandal, "One step synthesis of silver nanorods by autoreduction of aqueous silver ions with hydroxyapatite: an inorganicinorganic hybrid nanocomposite," Journal of Biomedical Materials Research, vol. 80, no. 2, pp. 391-398, 2007.

[45] A. D. Maynard, Nanotechnology: a research strategy for addressing risk, PEN 03. Washington DC: Woodrow Wilson International Center for Scholars, Project on Emerging Nanotechnologies, 2006.

[46] J. Jain, S. Arora, J. M. Rajwade, P. Omray, S. Khandelwal, and K. M. Paknikar, "Silver nanoparticles in therapeutics: development of an antimicrobial gel formulation for topical use," Molecular Pharmaceutics, vol. 6, no. 5, pp. 1388-1401, 2009.

[47] H. Cao and X. Liu, "Silver nanoparticles-modified films versus biomedical device-associated infections," Wiley Interdisciplinary Reviews, vol. 2, no. 6, pp. 670-684, 2010.

[48] K. Chaloupka, Y. Malam, and A. M. Seifalian, "Nanosilver as a new generation of nanoproduct in biomedical applications," Trends in Biotechnology, vol. 28, no. 11, pp. 580-588, 2010.

[49] F. Furno, K. S. Morley, B. Wong et al., "Silver nanoparticles and polymeric medical devices: a new approach to prevention of infection?" Journal of Antimicrobial Chemotherapy, vol. 54, no. 6, pp. 1019-1024, 2004.

[50] S. Abuskhuna, J. Briody, M. McCann et al., "Synthesis, structure and anti-fungal activity of dimeric $\mathrm{Ag}(\mathrm{I})$ complexes containing bis-imidazole ligands," Polyhedron, vol. 23, no. 7, pp. 1249-1255, 2004.

[51] T. Hamouda, A. Myc, B. Donovan, A. Y. Shih, J. D. Reuter, and J. R. Baker, "A novel surfactant nanoemulsion with a unique non-irritant topical antimicrobial activity against bacteria, enveloped viruses and fungi," Microbiological Research, vol. 156, no. 1, pp. 1-7, 2001.

[52] E. Berman, Toxic Metals and Their Analysis, Heyden, London, UK, 1980.

[53] A. Panáček, L. Kvítek, R. Prucek et al., "Silver colloid nanoparticles: synthesis, characterization, and their antibacterial activity," Journal of Physical Chemistry B, vol. 110, no. 33, pp. 16248-16253, 2006.
[54] C. Damm, H. Münstedt, and A. Rösch, "The antimicrobial efficacy of polyamide 6/silver-nano- and microcomposites," Materials Chemistry and Physics, vol. 108, no. 1, pp. 61-66, 2008.

[55] R. García-Contreras, L. Argueta-Figueroa, C. Mejía-Rubalcava et al., "Perspectives for the use of silver nanoparticles in dental practice," International Dental Journal, vol. 61, no. 6, pp. 297301, 2011.

[56] N. A. Amro, L. P. Kotra, K. Wadu-Mesthrige, A. Bulychev, S. Mobashery, and G. Y. Liu, "High-resolution atomic force microscopy studies of the Escherichia coli outer membrane: structural basis for permeability," Langmuir, vol. 16, no. 6, pp. 2789-2796, 2000.

[57] A. C. Mo, W. Xu, S. Q. Xian, Y. B. Li, and S. Bai, "Antibacterial activity of silver-hydroxyapatite/titania nanocomposite coating on titanium against oral bacteria," Key Engineering Materials, vol. 330-332, pp. 455-458, 2007.

[58] J. Liao, M. Anchun, Z. Zhu, and Y. Quan, "Antibacterial titanium plate deposited by silver nanoparticles exhibits cell compatibility," International Journal of Nanomedicine, vol. 5, no. 1, pp. 337-342, 2010.

[59] C. Y. Flores, C. Diaz, A. Rubert et al., "Spontaneous adsorption of silver nanoparticles on $\mathrm{Ti} / \mathrm{TiO}_{2}$ surfaces. Antibacterial effect on Pseudomonas aeruginosa," Journal of Colloid and Interface Science, vol. 350, no. 2, pp. 402-408, 2010.

[60] W. R. Li, X. B. Xie, Q. S. Shi, H. Y. Zeng, Y. S. Ou-Yang, and Y. B. Chen, "Antibacterial activity and mechanism of silver nanoparticles on Escherichia coli," Applied Microbiology and Biotechnology, vol. 85, no. 4, pp. 1115-1122, 2010.

[61] K. Kawahara, K. Tsuruda, M. Morishita, and M. Uchida, "Antibacterial effect of silver-zeolite on oral bacteria under anaerobic conditions," Dental Materials, vol. 16, no. 6, pp. 452-455, 2000.

[62] M. Danilczuk, A. Lund, J. Sadlo, H. Yamada, and J. Michalik, "Conduction electron spin resonance of small silver particles," Spectrochimica Acta, vol. 63, no. 1, pp. 189-191, 2006.

[63] S. Pal, Y. K. Tak, and J. M. Song, "Does the antibacterial activity of silver nanoparticles depend on the shape of the nanoparticle? A study of the gram-negative bacterium Escherichia coli," Applied and Environmental Microbiology, vol. 73, no. 6, pp. 1712-1720, 2007.

[64] C. Baker, A. Pradhan, L. Pakstis, D. J. Pochan, and S. I. Shah, "Synthesis and antibacterial properties of silver nanoparticles," Journal of Nanoscience and Nanotechnology, vol. 5, no. 2, pp. 244-249, 2005.

[65] A. Panáček, M. Kolář, R. Večeřová et al., "Antifungal activity of silver nanoparticles against Candida spp," Biomaterials, vol. 30, no. 31, pp. 6333-6340, 2009.

[66] D. R. Monteiro, L. F. Gorup, S. Silva et al., "Silver colloidal nanoparticles: antifungal effect against adhered cells and biofilms of Candida albicans and Candida glabrata," Biofouling, vol. 27, no. 7, pp. 711-719, 2011.

[67] D. R. Monteiro, S. Silva, M. Negri et al., "Silver nanoparticles: influence of stabilizing agent and diameter on antifungal activity against Candida albicans and Candida glabrata biofilms," Letters in Applied Microbiology, vol. 54, no. 5, pp. 383-391, 2012.

[68] S. Galdiero, A. Falanga, M. Vitiello, M. Cantisani, V. Marra, and M. Galdiero, "Silver nanoparticles as potential antiviral agents," Molecules, vol. 16, no. 10, pp. 8894-8918, 2011.

[69] A. S. AlGhamdi and S. G. Ciancio, "Guided tissue regeneration membranes for periodontal regeneration-a literature 
review," Journal of the International Academy of Periodontology, vol. 11, no. 3, pp. 226-231, 2009.

[70] N. U. Zitzmann, R. Naef, and P. Schärer, "Resorbable versus nonresorbable membranes in combination with Bio-Oss for guided bone regeneration," International Journal of Oral and Maxillofacial Implants, vol. 12, no. 6, pp. 844-852, 1997.

[71] J. Zhang, Q. Xu, C. Huang, A. Mo, J. Li, and Y. Zuo, "Biological properties of an anti-bacterial membrane for guided bone regeneration: an experimental study in rats," Clinical Oral Implants Research, vol. 21, no. 3, pp. 321-327, 2010.

[72] P. Podsiadlo, S. Paternel, J. M. Rouillard et al., "Layer-bylayer assembly of nacre-like nanostructured composites with antimicrobial properties," Langmuir, vol. 21, no. 25, pp. 11915-11921, 2005.

[73] S. S. Jensen and H. Terheyden, "Bone augmentation procedures in localized defects in the alveolar ridge: clinical results with different bone grafts and bone-substitute materials," The International journal of oral and maxillofacial implants, vol. 24, pp. 218-236, 2009.

[74] K. D. Secinti, H. Özalp, A. Attar, and M. F. Sargon, "Nanoparticle silver ion coatings inhibit biofilm formation on titanium implants," Journal of Clinical Neuroscience, vol. 18, no. 3, pp. 391-395, 2011.

[75] Q. Ma, S. Mei, K. Ji, Y. Zhang, and P. K. Chu, "Immobilization of $\mathrm{Ag}$ nanoparticles/FGF-2 on a modified titanium implant surface and improved human gingival fibroblasts behavior," Journal of Biomedical Materials Research, vol. 98, no. 2, pp. 274-286, 2011.

[76] R. L. Williams, P. J. Doherty, D. G. Vince, G. J. Grashoff, and D. F. Williams, "The biocompatibility of silver," Critical Reviews in Biocompatibility, vol. 5, no. 3, pp. 221-243, 1989.

[77] M. Mahmood, Z. Li, D. Casciano et al., "Nanostructural materials increase mineralization in bone cells and affect gene expression through miRNA regulation," Journal of Cellular and Molecular Medicine, vol. 15, no. 11, pp. 2297-2306, 2011.

[78] C. E. Albers, W. Hofstetter, K. A. Siebenrock, R. Landmann, and F. M. Klenke, "In vitro cytotoxicity of silver nanoparticles on osteoblasts and osteoclasts at antibacterial concentrations," Nanotoxicology. In press.

[79] W. Liu, Y. Wu, C. Wang et al., "Impact of silver nanoparticles on human cells: effect of particle size," Nanotoxicology, vol. 4, no. 3, pp. 319-330, 2010.

[80] S. M. Hussain, K. L. Hess, J. M. Gearhart, K. T. Geiss, and J. J. Schlager, "In vitro toxicity of nanoparticles in BRL 3A rat liver cells," Toxicology in Vitro, vol. 19, no. 7, pp. 975-983, 2005.

[81] C. Carlson, S. M. Hussein, A. M. Schrand et al., "Unique cellular interaction of silver nanoparticles: Size-dependent generation of reactive oxygen species," The Journal of Physical Chemistry B, vol. 112, no. 43, pp. 13608-13619, 2008.

[82] C. Greulich, J. Diendorf, J. Geßmann et al., "Cell type-specific responses of peripheral blood mononuclear cells to silver nanoparticles," Acta Biomaterialia, vol. 7, no. 9, pp. 35053514, 2011.

[83] J. S. Hyun, B. S. Lee, H. Y. Ryu, J. H. Sung, K. H. Chung, and I. J. Yu, "Effects of repeated silver nanoparticles exposure on the histological structure and mucins of nasal respiratory mucosa in rats," Toxicology Letters, vol. 182, no. 1-3, pp. 24-28, 2008.

[84] Y. S. Kim, J. S. Kim, H. S. Cho et al., "Twenty-eight-day oral toxicity, genotoxicity, and gender-related tissue distribution of silver nanoparticles in Sprague-Dawley rats," Inhalation Toxicology, vol. 20, no. 6, pp. 575-583, 2008. 

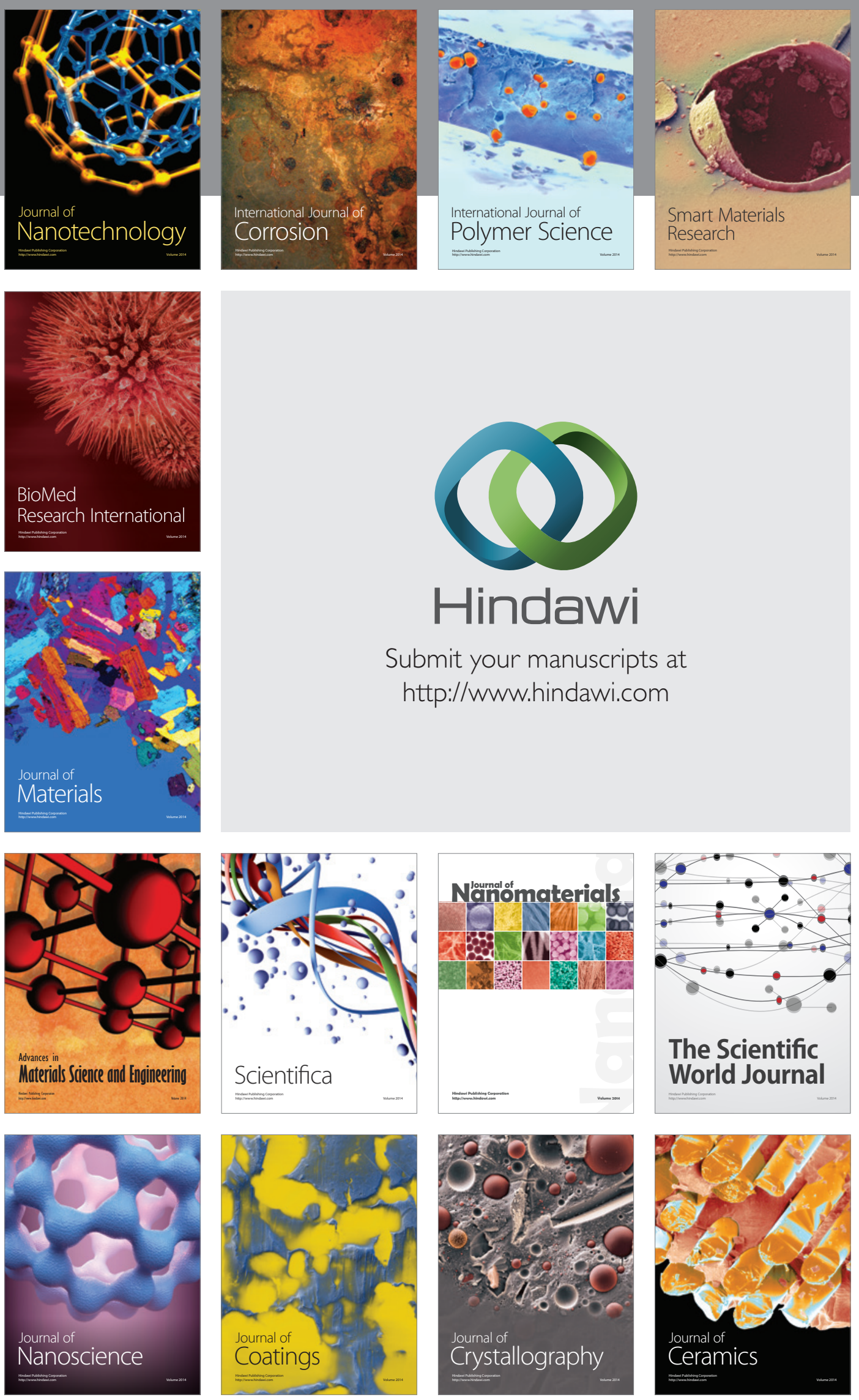

The Scientific World Journal

Submit your manuscripts at

http://www.hindawi.com

\section{World Journal}

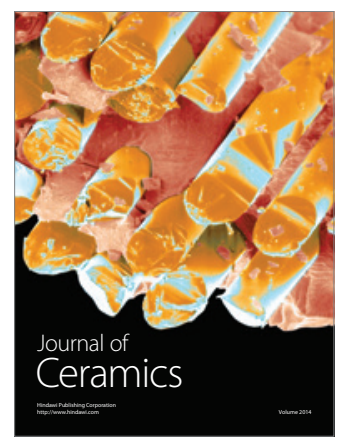

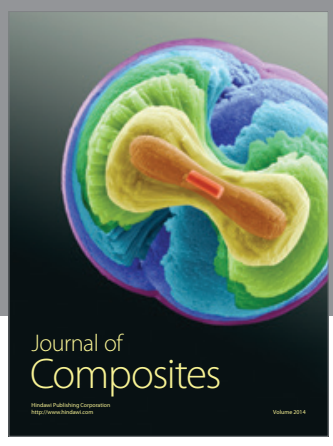
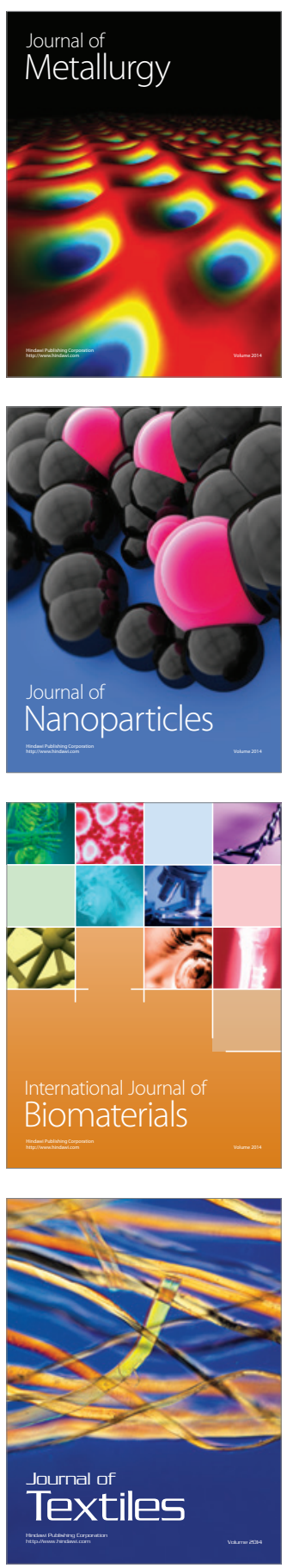